\title{
Applications of visual magnitude in forest planning: A case study
}

\author{
by Brent C. Chamberlain ${ }^{1, *}$, Michael J. Meitner ${ }^{2}$ and Robert Ballinger ${ }^{3}$
}

\begin{abstract}
Recent impacts from the Mountain Pine Beetle epidemic, the lack of available timber in areas of lower elevation, and the reduction in back-country timber has pushed forest operations into publicly significant and visible landscapes. When these become the stage for operations they can be a source of public backlash. These kinds of landscapes are carefully protected by governments, yet, this protection may reduce timber availability. We have developed a new GIS-based tool to aid planners in designing harvests in these areas. Our tool is applied to three case studies in British Columbia to showcase how it can reduce planning time, increase timber availability and limit the negative visible effects of operations.
\end{abstract}

Keywords: Visual Magnitude, Viewshed, Visual Resource Management, Planning, GIS, Visibility, Visually Sensitive Areas

\section{RÉSUMÉ}

Les conséquences récentes de lépidémie de dendroctone du pin ponderosa, la pénurie de bois disponible dans les régions de faibles altitudes et la réduction de la disponibilité des bois de l'arrière-pays ont fait en sorte que les opérations d'exploitation forestière se font maintenant dans des paysages beaucoup plus visibles aux yeux du public. Lorsque ceux-ci sont deviennent la scène des opérations, ils peuvent devenir une source de mécontentement public. Ce type de paysage est soigneusement protégé par les gouvernements, mais cette protection peut entraîner une réduction de la disponibilité en matière ligneuse. Nous avons élaboré un nouvel outil établi à partir d'un système d'information géographique (SIG) dans le but d’aider les planificateurs à concevoir les blocs d'exploitation sur ces superficies. Notre outil est utilisé dans le cas de trois études réalisées en Colombie-Britannique afin de démontrer comment il permet de réduire la durée de la planification, d’accroître la disponibilité de la matière ligneuse et de limiter les impacts visuels négatifs des opérations.

Mots clés : amplitude visuelle, Viewshed, aménagement visuel des ressources, planification, SIG, visibilité, zones visuellement sensibles

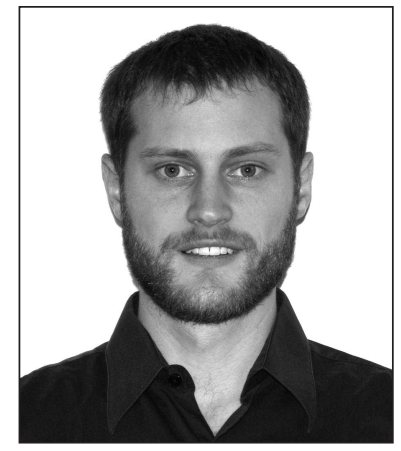

Brent C. Chamberlain

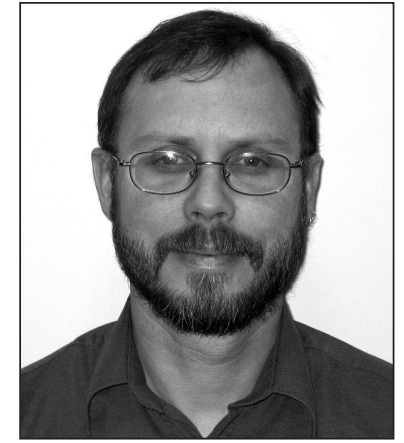

Michael J. Meitner

\section{Introduction}

Scenic beauty is an attribute of the natural world that has long been important to humans. It has inspired us to create great works of art; to paint, to write, to sing. It nurtures our mind and body. Recent research has even found that it may help us to fight off cancer (Li et al. 2007, Li et al. 2008a, Li et al. $2008 \mathrm{~b}$ ). This is merely an extension of what we have long known about the restorative and stress-reducing nature of beautiful landscapes (Ulrich 1986, Parsons 1991, Kaplan

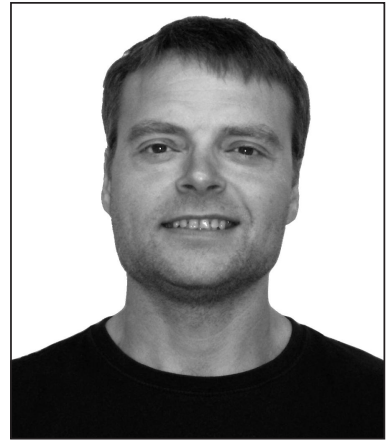

Robert Ballinger
1995, Frumkin 2001,Parsons and Daniel 2002) and it is likely that there are undiscovered health benefits associated with exposure to natural scenic beauty. In the light of studies that have documented the link between exposure to nature and stress reduction as well as stress inoculation (Ulrich 1986, Ulrich et al. 1991), it seems that by increasing the amount of natural scenic beauty in and around places we live and explore might reduce stress and associated complications. This is an important consideration when an estimated 20\% of Canadian workers experience a stressrelated illness every year (Statistics Canada 2003) and that stress-related absences are estimated to cost employers about CAD $\$ 3.5$ billion each year (Duxbury and Higgins 2001).

The protection of the scenic beauty of forested landscapes has long been a concern of foresters and is increasingly important as people interface more and more with forests in their daily lives. This is especially true in areas close to

\footnotetext{
${ }^{1}$ Kansas State University, Landscape Architecture and Regional \& Community Planning, Manhattan, KS 66502, USA. ${ }^{\star}$ Corresponding author's email: brentchamberlain@ksu.edu

${ }^{2}$ University of British Columbia Forest Resources Management Vancouver, BC V6T 1Z4 Canada

${ }^{3}$ West Fraser Mills Ltd. 1138 Melville St., Suite 407 Vancouver, BC V6E 4S3
} 
human settlements. In North America there is an increasing trend of wildland urban interface/intermix style development (Radeloff et al. 2005). This continues to put pressure on areas that were once remote and infrequently visited, to comply with a high degree of visual protection. In addition to settlement pressures, recreational use of forested lands also creates a higher demand for landscapes that possess high levels of scenic beauty. In areas where forestry has traditionally been the mainstay of local economies, this can cause conflicts to arise. Since the time of Gifford Pinchot, it has been commonplace for foresters to manage for multiple uses, and while this conflict between timber production and alternate uses of the forest is not new, the expectations seem to always creep higher as our technology allows for higher productivity along multiple management variables simultaneously (e.g., increasing timber volumes while achieving higher standards of visual protection).

Given the vast rugged landscapes of steep topography and immense forests in British Columbia (BC), Visual Resource Management (VRM) has a long tradition in the Province. In BC, the Ministry of Forests has identified particularly aesthetic areas in the province as "visually sensitive areas". They are designated in order to provide some level of visual protection against human-induced disturbances. The BC Ministry of Forests outlines how forestry companies can manage these sensitive areas (BC Ministry of Forests 2001b, Marc 2008), and requires that modifications from forest activities be limited to achieve specific visual quality objectives set by the Ministry (BC Ministry of Forests 2004).

A major part of this management deals with visual quality assessments, completed for the Ministry to ensure that the integrity of scenic areas is being upheld. The BC Ministry of Forests has established a process for ensuring that visually sensitive areas are maintained throughout the province. This process as applied to project plans consists of six phases:

1. Visual Landscape Inventory (VLI)

a. To delineate Visually Sensitive Areas (VSA)

b. Further delineation of visually sensitive areas into visual sensitivity units (VSUs)

2. Recommend Visual Quality Classes

3. Approved Visual Quality Objectives (VQO)

4. Visual simulations and design solutions

5. Achieved visual conditions

6. Program audits - monitoring/inspections of field activities

Each Visually Sensitive Unit (VSU) has an established Visual Quality Objective (VQO) which specifies the degree of visual impact on the landscape. The range of impact will fall between Preservation, which allows for very small impacts designed to be indistinguishable from existing landscape, and Maximum Modification, whereby the harvest is very apparent both in size and shape, e.g., block-like (BC Ministry of Forests 2004). The range from least to highest regulated impact is: Preservation, Retention, Partial Retention, Modification and Maximum Modification. A VQO is legally binding as a Government Actions Regulation in British Columbia; failure to meet these objectives may result in fines (BC Ministry of Forests 2004) so it is imperative that planning be done carefully. The BC Ministry of Forests has provided a number of guidelines, manuals and case studies intended to aid practitioners in developing harvest plans to meet the objectives
(BC Ministry of Forests 1994a, 1994b, 1994c, 1994d, 1996, 1997a, 1997b, 2001a, 2001b; Marc 2008). Most recently, the Effectiveness Evaluation (Marc 2008) was produced to guide planners through the process by providing a structured method for understanding how evaluations of harvest designs should be carried out.

One of the key elements of harvest block design within a VSU is to minimize the visual impact, particularly as the regulated VQO nears Preservation. Typically this means reducing the amount of visible harvest from important viewing locations such as highway corridors, scenic stops, and recreational vistas. Often the first step in identifying locations for placing harvests is to use a viewshed analysis. Viewsheds are useful because they identify locations on the landscape that are visible or not. These provide an intuitive way to spatially identify if a harvest block will be visible, and how much of the block will be visible. Another advantage of these analyses is that they can be used in tandem with 2D planimetric maps, making it very easy to overlay the analysis with other data layers, such as road networks and forest cover. In some cases, viewsheds may provide ample information to best locate and effectively minimize the visual impact of the harvest blocks. However, in many cases, viewsheds alone are insufficient. For instance, consider a landscape where an individual looks out and sees a seamless landform with no hidden areas. The only potential to screen these areas are when trees in front of the harvest hinder detection of landscape change. Unless the harvest size is quite small or selective harvesting is used, it is highly likely that an individual would see evidence of harvesting.

Developing harvest designs under this circumstance requires careful and precise planning, where standard GIS tools may not be sufficient to support the creation of these more detailed designs. Thus, many forestry companies have turned to alternative methods for preparing harvest designs. One of the more popular methods uses 3D computer visualizations to simulate the proposed plans in order to assess the potential visual impacts. Often the technology employed is a computer graphics program called Visual Nature Studio (VNS) or World Construction Set (VNS is the most recent version of the software). VNS has the capability to quickly generate near photo-realistic models of landscapes using detailed forest cover data.

As helpful as this software can be, the process of developing a plan and modeling it in $3 \mathrm{D}$ requires significant effort and resources. Besides the cost of the software, the program requires a certain degree of technical expertise to use. If a company is fortunate to have a planner who is skilled both in GIS and VNS, then the primary limitation is in the time it takes to develop and digitally render a harvest block. Otherwise companies may find that it takes two or more people and many hours to design a block, integrate it within the GIS and render the design.

In either case, in order to render the image in 3D, planners must first develop a 2D map of their plan in GIS. This spatial information is then passed to VNS and the post-harvest landscape is rendered. From this rendering, the design is evaluated against the VQO set for the area. Part of this process involves measuring the amount of space on the landform where the harvest block is visible. This requires the use of additional software to effectively calculate the number of pixels where modification is visible and divide that by the num- 
ber of pixels of the entire landform. This number represents the percent of visible alteration (PVA), a critical element of the Visual Impact Assessment process (see Marc 2008).

The primary cost of this process is in the number of times that a harvest block must be altered from its original design to comply with the established VQO. Each time an evaluation is carried out, the planner needs to improve its visual character by modifying the plan view boundary, updating the GIS to reflect these changes, and rendering a new visualization to determine if the desired degree of visual protection has now been achieved. This becomes an iterative process where employee time can become very expensive. Thus, anything that can be done to streamline this process and reduce the number of iterations would be helpful.

Theoretically, Visual Magnitude (VM) (Iverson 1985) provides a way to calculate the perspective visible alteration of a proposed harvest without any rendering in 3D. To do this, VM assesses the topographical terrain data from the viewer's perspective by calculating distance, slope and direction of the view and topography (Chamberlain and Meitner 2013). VM is calculated based on a digital elevation model (DEM), so the resolution of the analysis is dependent upon the resolution of the DEM. The output provides an objective quantitative value for each cell of the DEM (represented as discrete units) that ranges from not visible $(0 \%)$ to the only object that is visible $(100 \%)$. If the cell were to have a value of $100 \%$, it would mean that it is the only visible area and entirely occupies the viewer's perspective. The output is a single grid raster that can be used to overlay with other map layers to quickly assess the amount of alteration that has occurred from an individual viewpoint. Details of the method, the calculation and extensive description can be found in Chamberlain and Meitner (2013).

As a concept, VM has existed for some time in visual design. Travis et al. (1975) developed the computer program VIEWIT, which could calculate these values. Iverson (1985) documented VM more thoroughly, showing how these calculations could be produced as well as the rationality behind them. Many related methods have been produced since Iverson's original work (Chamberlain and Meitner 2013). While modifications and improvements to the original method have been made, the fundamental emphasis of improving the binary viewshed has remained, but uptake by industry has been nearly nonexistent. This is due in part to modern GIS software packages used by industry that do not provide a push-button tool to calculate VM or visual exposure values. With this in mind, we created software that is capable of producing a VM analysis that can be easily incorporated into any current GIS software (Chamberlain and Meitner 2013) and worked with industry to present a proof-of-concept study.

This paper outlines three case studies in which our software was used in collaboration with West Fraser Mills Ltd. (West Fraser) in Tree Farm License (TFL) 52 located near Quesnel, BC. The first example outlines how VM was used to strategically place reserves to minimize visual impact of a block that was already approved. The second case study illustrates how VM was used to design a block from scratch. Lastly, we explain how VM was used to incorporate a sequence of multiple viewpoints along a popular canoe route into the planning process, expanding visual protection as these viewpoints were not a part of current visual protection in the area.

\section{Case studies}

Through the fall of 2011, the case studies were carried out by West Fraser to continue the research and development of the software in a real-world situation. The studies took place within Tree Farm License (TFL) 52, encompassing the Barkerville Highway, a historic corridor connecting Quesnel to Barkerville and on to Bowron Lake Provincial Park. Due to recent impacts from the Mountain Pine Beetle epidemic, the decreasing value of timber, the lack of available timber in areas of lower elevation, and the reduction in back-country timber, West Fraser's operations had been pushed into higher elevation areas which included publicly significant and more visible landscapes, many of which fell under the protection of visually scenic areas. Within the region are many mountains, hills, steep valleys and lakes. Culturally, the corridor to the Provincial Park is host to small towns, historical sites and a ski resort.

West Fraser is actively harvesting within the corridor. As of summer 2012, nearly a dozen blocks had been harvested, totalling over 500 hectares. In the next few years, nine more blocks, totalling over 400 hectares, are due for harvesting.

The studies focused on developing analyses along the main highways, roads and significant viewpoints, and also included an analysis of a canoe route on Bowron Lake. The focus areas were in the mid-distance view (one to eight $\mathrm{km}$ within these areas). The studies were intended to validate our software: to see if our product could reduce the costs associated with VRM planning by streamlining the process of designing and rendering plans in $3 \mathrm{D}$, and to free up valuable time which highly trained, specialized personnel spend on planning tasks.

Three examples are shown in order to demonstrate how the model was used and the benefits and insights created as a result of the process. The three areas are located in distinctively different places in the TFL. Fig. 1 shows the vicinity of the three locations where analyses have been created and the software applied.

\section{Example I: Highway 97 North (35U)}

In this example, the model was used to locate reserves (unharvested retention patches) within a block already slated for harvest. The reserves were required in order to maintain a certain amount of the original vegetation as Wildlife Tree Patches (WTP). Additional retention was also needed such that the block would meet the established VQO (partial retention). Though the reserves and retention are required for wildlife and visual purposes, their spatial location is not explicitly defined in law. Our analysis software can be used to identify areas to place the reserves to help minimize the visual impact. Fig. 2 is an overview of the example area showing a viewpoint that was used to conduct the visual assessment.

Large regions are shown where the darker shade represents a higher range of VM. The harvest block is outlined as a thin gray line. Within the block are polygon hashes showing the location of the reserve patches. Notice that many of the reserves lie near or over the areas of higher VM. Our software was able to efficiently produce the VM analysis that could be intuitively used to determine the particular locations within a block where clearcut land would be most exposed if it was visible from the viewpoint. This is an improvement over the typ- 


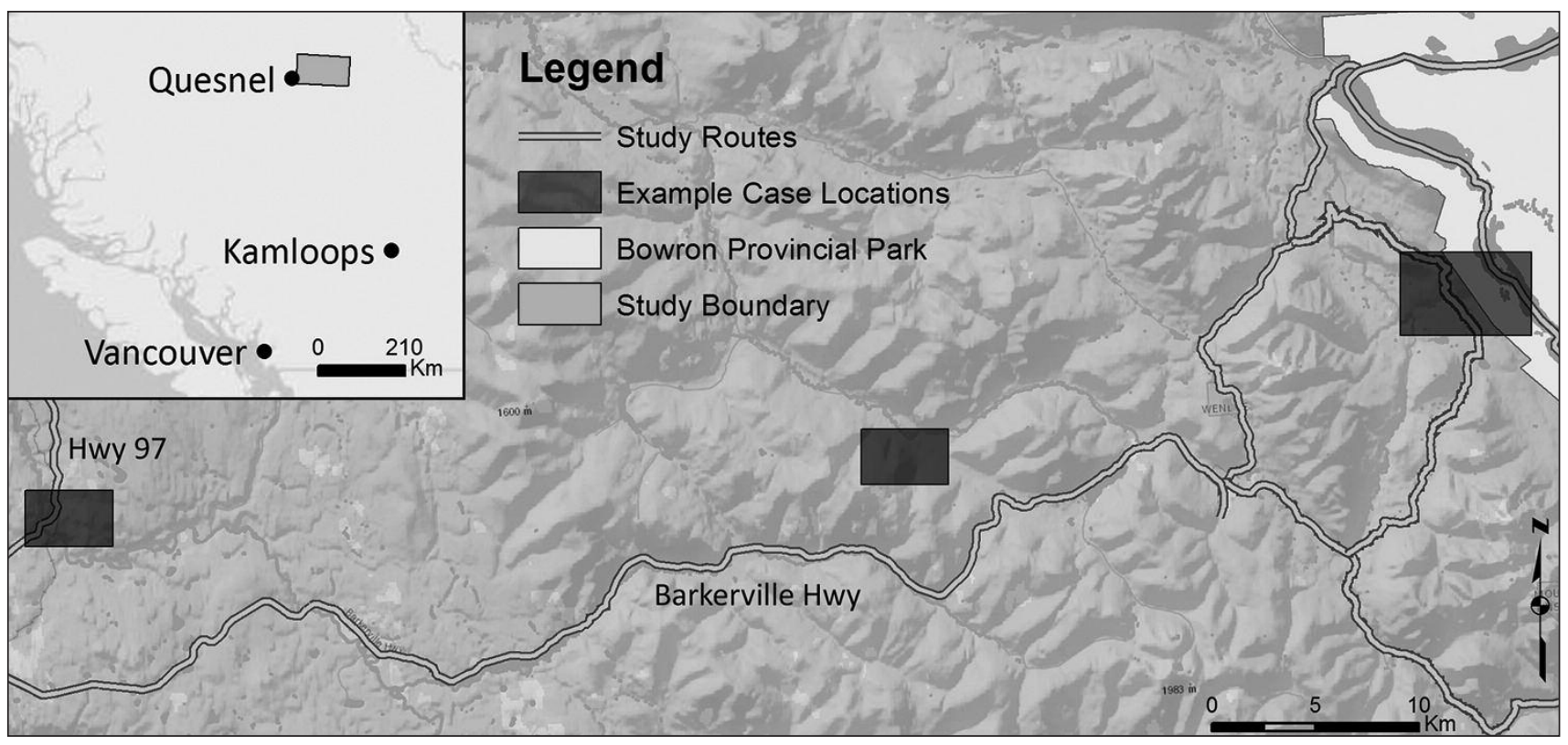

Fig. 1. Case study example locations

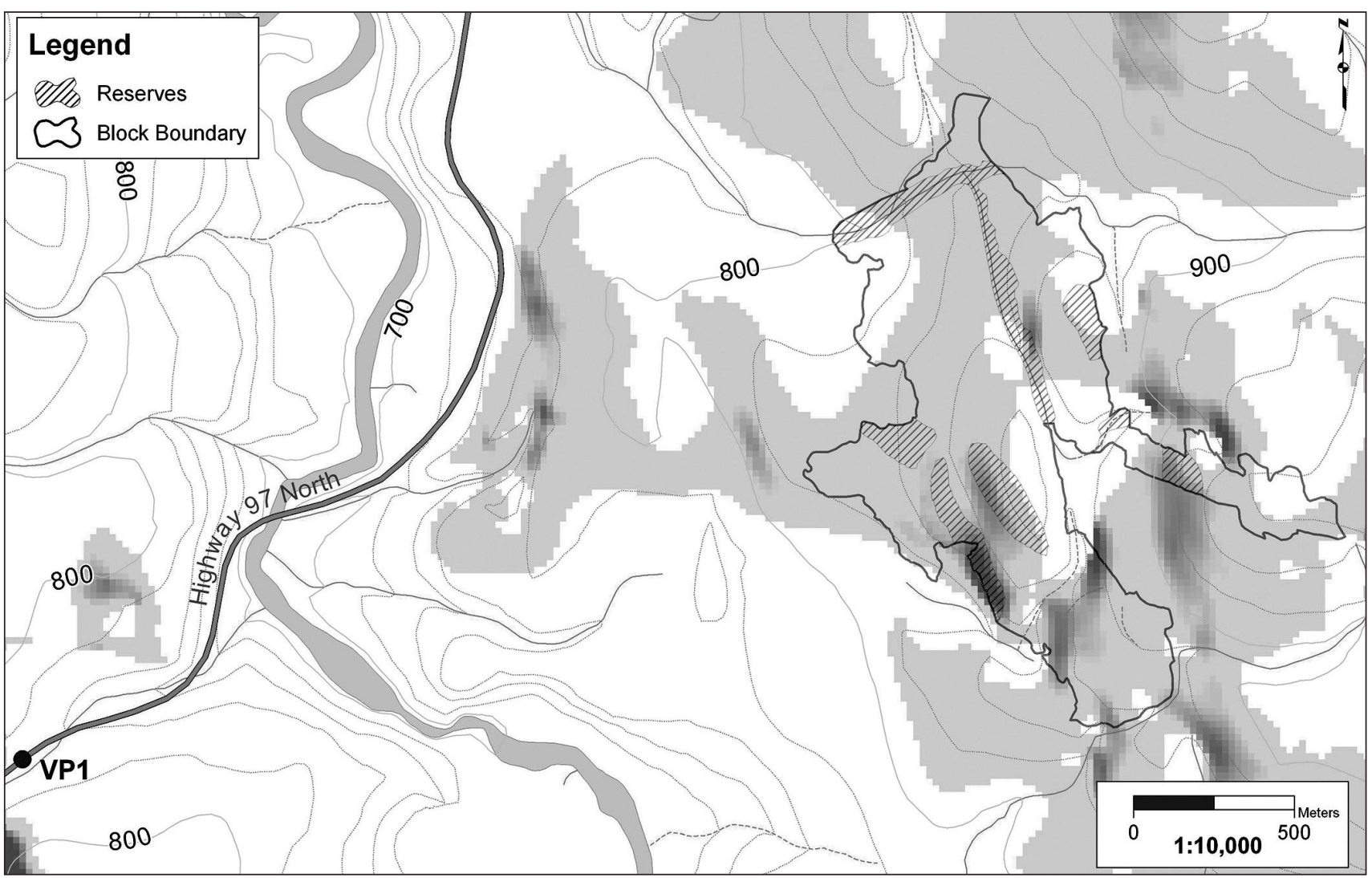

Fig. 2. Example I: Overview with Visual Magnitude Analysis and viewpoint

ical viewshed used by forest planners (i.e., the standard binary output available from ESRI's ArcGIS ${ }^{\circ}$. This means that by screening areas of higher VM, West Fraser could reduce the percent of visible alteration with the same amount of retention. Though the design in 2D shows one large harvest with a few small WTPs, the perspective view looks substantially dif- ferent. Fig. 3 shows the outcome of a 3D rendering of the harvest block (left) and the same harvest without the strategically placed reserves (right). In the figure, the areas designated " $\mathrm{A}$ " show pre-existing pine salvage from a wood-lot license, whereas " $\mathrm{B}$ " shows the region of the new harvest block. There are substantial visible differences between the harvest with 


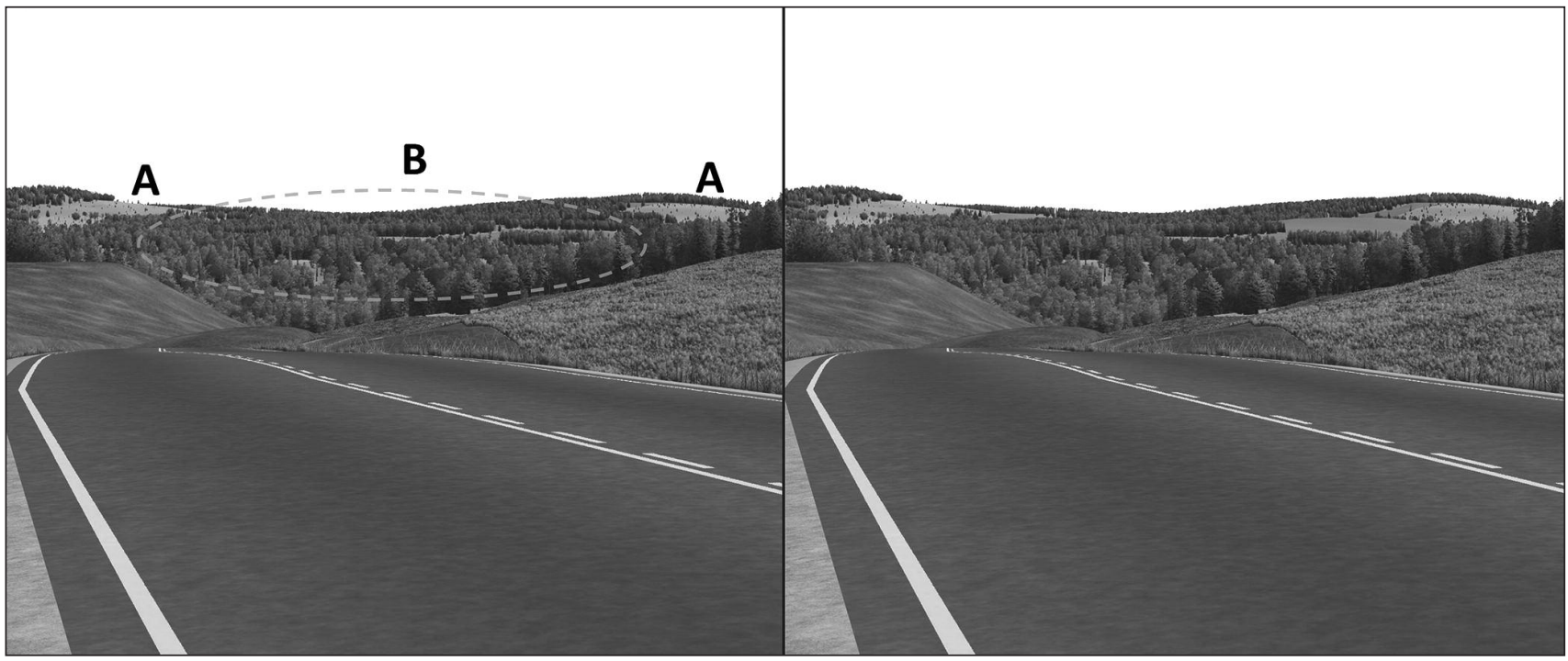

Fig. 3. Example I: $3 D$ rendering from viewpoint showing planned harvest

the strategically placed WTPs and with those reserves removed. While Fig. 2 shows that a large continuous portion of the landscape was harvested, the net effects of the wellplaced WTPs limit the visual impacts by reducing the visible area in perspective view (as compared with the no WTP version) and creates visual breaks making the single block appear as small distributed harvests. Even with the sloping terrain, where much of the landform was harvested, the actual visual impact is quite mitigated as a result of strategic reserve placement.

Previous to the VM maps being produced, West Fraser had undertaken attempts to locate reserves within the designated block. During these efforts, the planner had developed three possible block designs, including varying the reserve locations. A few of the designs were rendered using VNS, but none achieved the desired outcome. After the VM maps were produced, the planner quickly identified the reserve locations, placing the blocks strategically over the higher VM areas within the block. A 3D rendering of this design was produced, and immediately the desired outcome was achieved, as shown in Fig. 3. The benefits of using VM in this example were significant. First, it reduced much of the guesswork and associated time. Second, it provided an increased level of confidence that what was seen in 2D would translate well in the 3D setting. Third, it increased the available timber by guiding the design of the reserve shape, requiring less timber to be reserved in order to meet the VQO.

\section{Example II: Highway Corridor (586)}

In Example II, planners were tasked with not only placing reserves, but defining the boundary of the harvest block. Fig. 4 shows the outcome of the design process with two blocks outlined in gray. Planners had to work within pre-established operational constraints, such as the road network shown as the dotted gray lines. Notice how the planner avoided areas of higher VM, except where the road crossed directly through these areas. The design was based around the VM analysis and reserves were added afterwards using a similar strategy as demonstrated in Example I. Although some difficult terrain conditions limited a fully VM-based design, the planner still benefited from using the analysis. In the case of Example II, no previous design had been developed, and the planner found that by employing the VM analysis, the first design accomplished the desired outcome. Again, the analysis saved time providing an increased harvest area by minimizing the reserve areas set aside to meet the VQO, while still working carefully within the requirements of the established VQO. The proposed design was rendered in $3 \mathrm{D}$ and is shown in Fig. 5 (left). As a comparison, an example of a poor visual design on the same landscape is shown in Fig. 5 (right).

The differences between the well-planned and poorly planned designs are clearly obvious, particularly with the large exposed hillside (shown on the right side of the right figure). In this scenario, West Fraser found it was not only easier to locate the WTP, but the shape design itself was easier to create. As required by the established VQO (partial retention), the shape needed to appear more organic, irregular and natural. By following the topography of the VM analysis, these aspects of shape design were intuitively produced on the first attempt (Fig. 5, left). In addition, the planner also saved time ground-truthing the design. Ground-truthing is typically a time-intensive step in the design process requiring a site visit to explore the area to identify potential problems. By using a VM-based design to identify the location of WTP, planners were able to reduce the amount of time they spent on site because the designated WTP areas did not have to be explored. This provided more time to carefully consider the operational and design aspects in the visible areas which could be harvested.

\section{Example III: Bowron Lake Canoe Route [686]}

In Example III, West Fraser was interested in modeling the potential impacts of harvesting activities where VQOs were not established but may actually be visible from within the park. In this particular situation there were no pre-established viewpoints. In fact, identifying exact viewpoints would be difficult due to the fact that the views are often seen from along a canoe route whose location can vary substantially. 


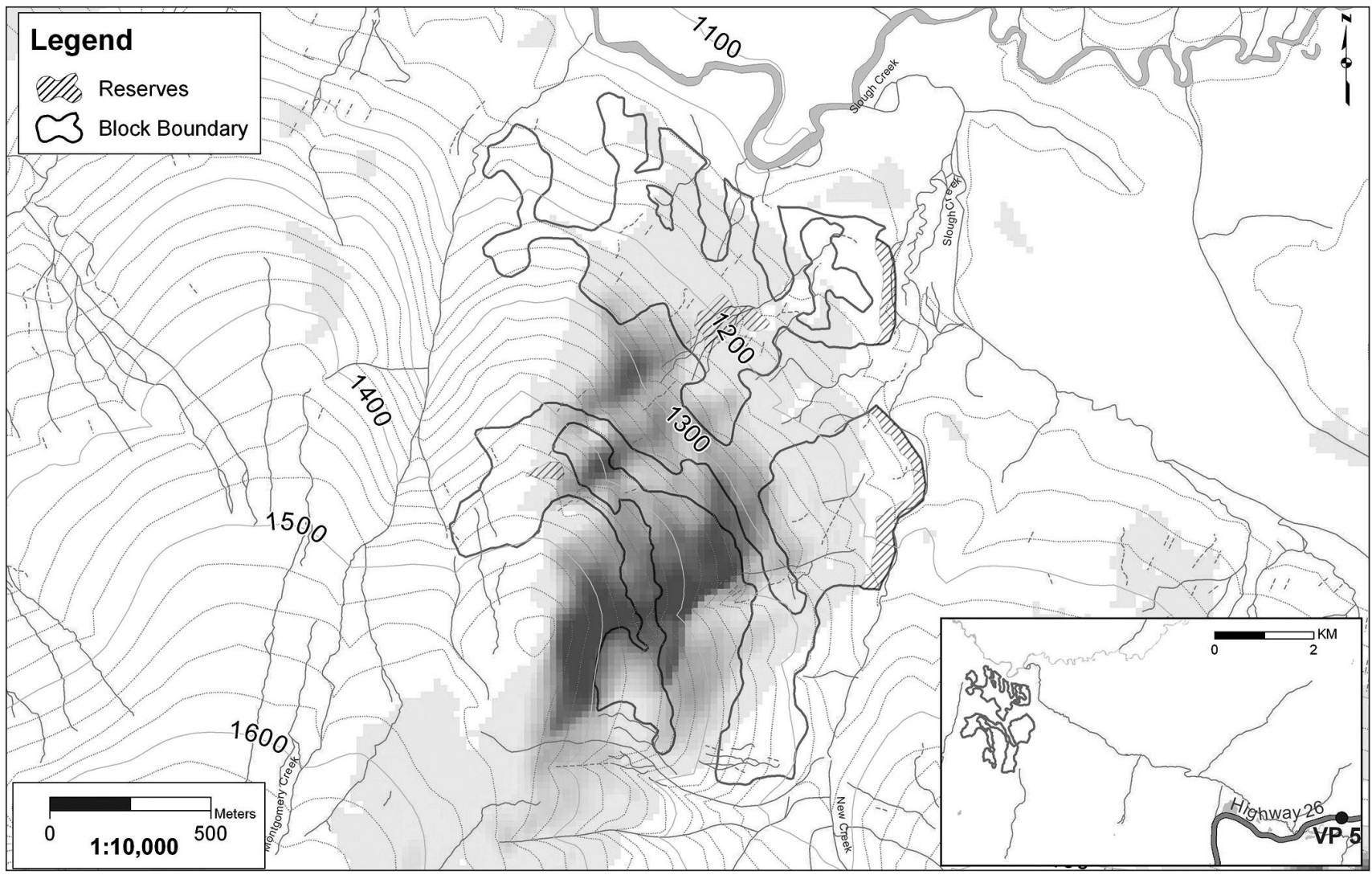

Fig. 4. Example II: Overview with Visual Magnitude Analysis and viewpoint

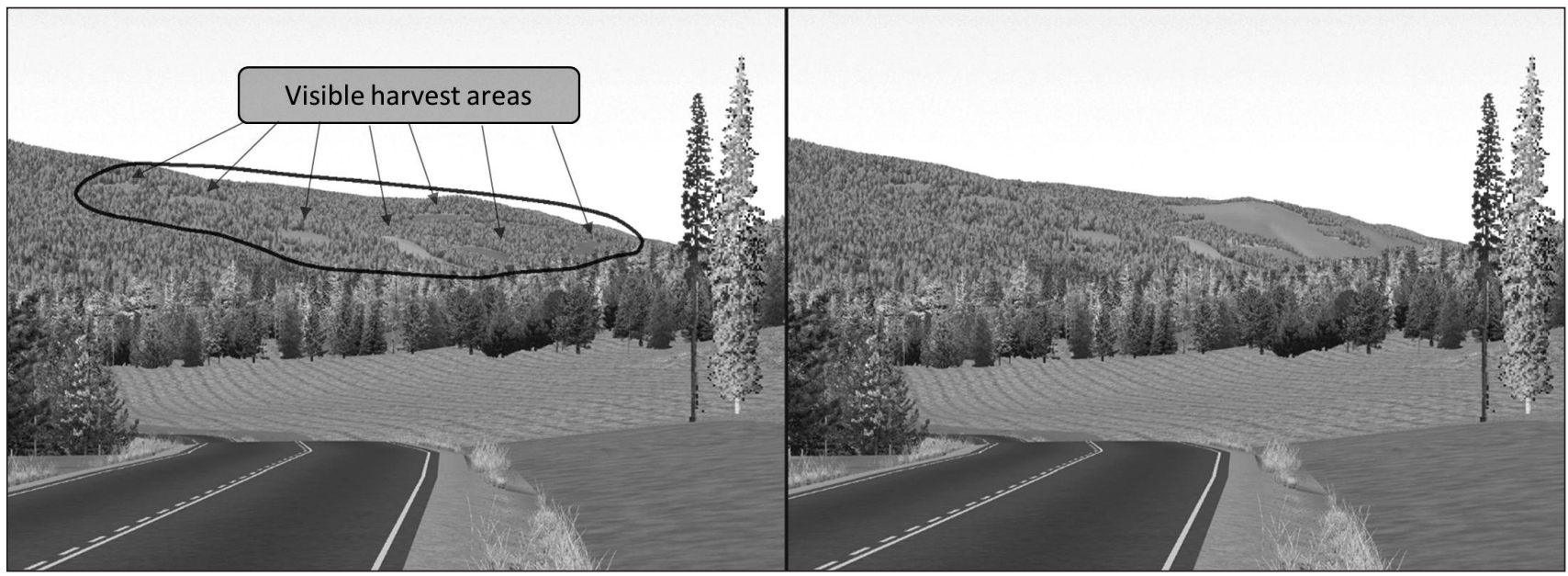

Fig. 5. Example II: 3D rendering from viewpoint 1 showing planned harvest

Here we used the opportunity to explore using the model to simulate the average VM from along a canoe route in the middle of the lake. This method moves away from emphasizing the significance of one (or few) viewpoint(s), toward the use of numerous viewpoints along a linear feature or route. The concept driving this approach is that certain kinds of experiences may not be accounted for or best represented by one or few viewpoints. This is particularly true in situations where no viewpoints or observation locations are well-defined (e.g., campsites or scenic pull-outs) or where the experience of a landscape is made through time (e.g., highway drive, canoeing, kayaking). Notice the analysis and route in Fig. 6.

In Fig. 6, one can see that a vast expanse of visible areas on the hillside consists of high average VM, and that these areas are spatially distributed over the entire landscape. This distribution is caused by the averaging of all VM results from sample views along the $50 \mathrm{~km}$ of the canoe route. With this analysis, planners can get a better idea of the potential and average effect of harvesting activities within a region based on the views from along the route. Though this may provide some 


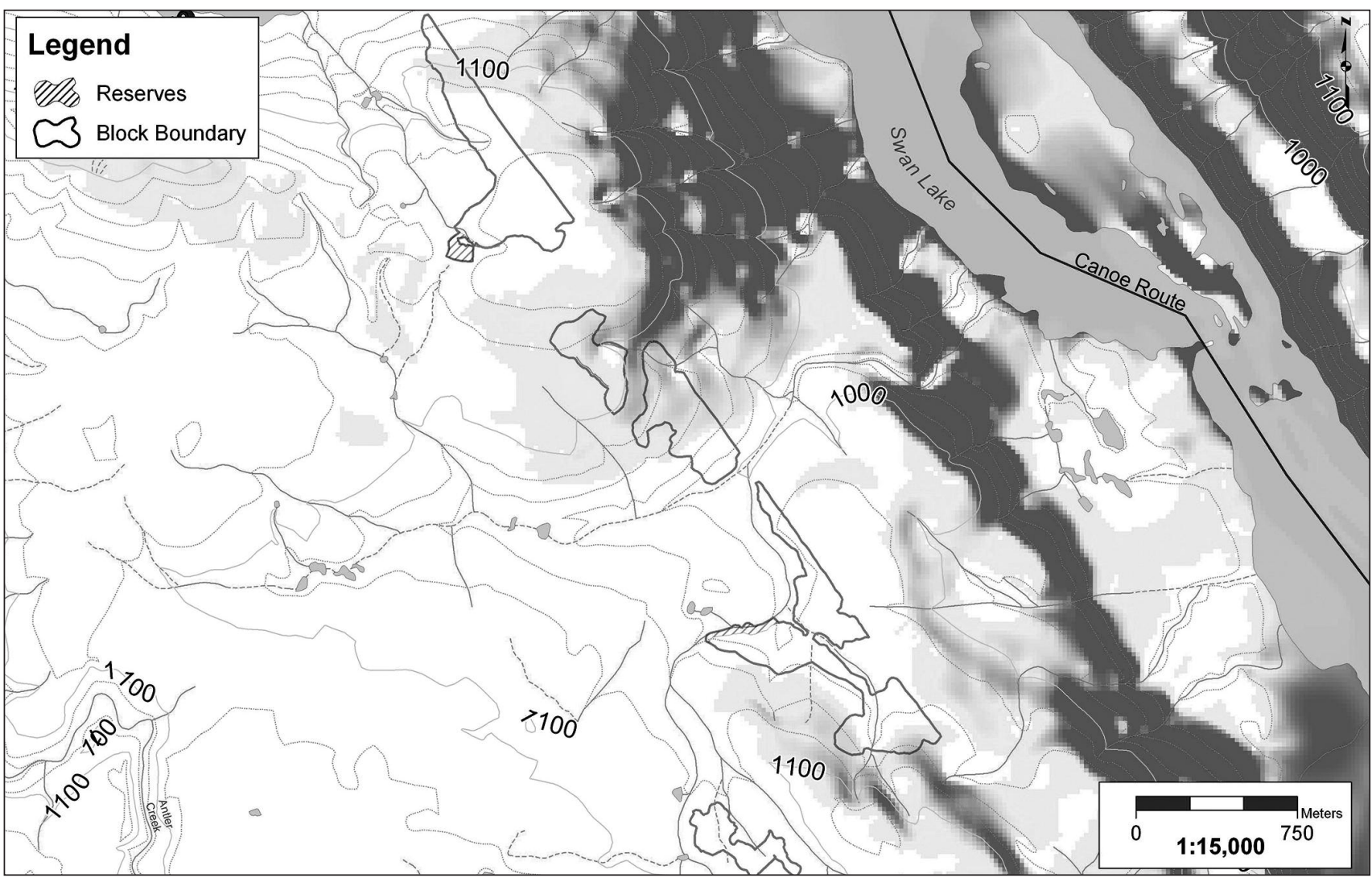

Fig. 6. Example III: Overview with Visual Magnitude Analysis and linear feature (canoe route)

advantages, it is not meant to identify the worst possible impact which may be perceived from any single view. Rather, it is intended to simultaneously consider the average impact across all possible views.

For this particular scenario, West Fraser had already obtained permits to harvest near the designated blocks shown in Fig. 6. In these areas no existing VQO had been established, so previous to the VM analysis, the blocks were designed using objectives other than visual quality. When the VM analysis was later produced using the canoe route, some of the harvestable area was identified as being potentially visible. Upon further investigation using 3D techniques, the planners concurred that if the original harvest design was completed, the harvested area may be visible. Though no pre-existing VQO had been established for these areas, planners understood that the existing block design and subsequent harvest may impact the visual quality from Swan Lake within Bowron Lake Provincial Park. As a result, the proposed boundaries for blocks 2 and 3 were redesigned. For block 2, the boundaries were altered by splitting the block into two smaller units separated by an area of higher VM. In block 3, the size was reduced where it crossed an area of higher VM. Regarding block 1, no changes were made as the amount of potential visible area is low and of those visible, the VM is also low.

In order to validate the visual effects of the redesigned blocks, planners created several 3D renders from arbitrary sample viewpoints along the canoe route. Two examples of these renderings are shown in Fig. 7 and Fig. 8. The effects of the simulated harvest are identified using black arrows. Notice how the treeline causes a slight break on the horizon. Though this is visible in the image, the harvest itself is not easy to identify as it is being hidden by effective design and by forest cover in front of the block. The sharp edges could be reduced by adding a small amount of edge feathering. In either case, the visible effects are quite mitigated.

Example I and II showcased scenarios in which viewpoints and VQOs had already been established, yet in Example III neither had been developed. Using a hypothetical canoe route to produce the VM analysis, the planner was able to easily identify potential impacts which were previously not foreseen. Though a more simplified analysis could be performed using a standard viewshed model, VM provided more specific information regarding the relative VM throughout the entire landscape. In so doing, the analysis enabled the planner to mitigate impacts by reducing the harvest size in areas of higher VM. Furthermore, in using a linear route, rather than single-sample viewpoints, the analysis is more likely to reflect the viewers' perspectives as they paddle through the lakes. Since it is likely the travelling viewers would remember, or be impressed by, a large dominant ridge that was visible for a good length of the trip, planners can use the average VM value to mitigate impacts to this ridge.

\section{Discussion and Conclusion}

Three major benefits were realised in this study. The first is a reduction in planning time. Planning in areas where a VQO exists often necessitates validation of block designs using $3 \mathrm{D}$ 


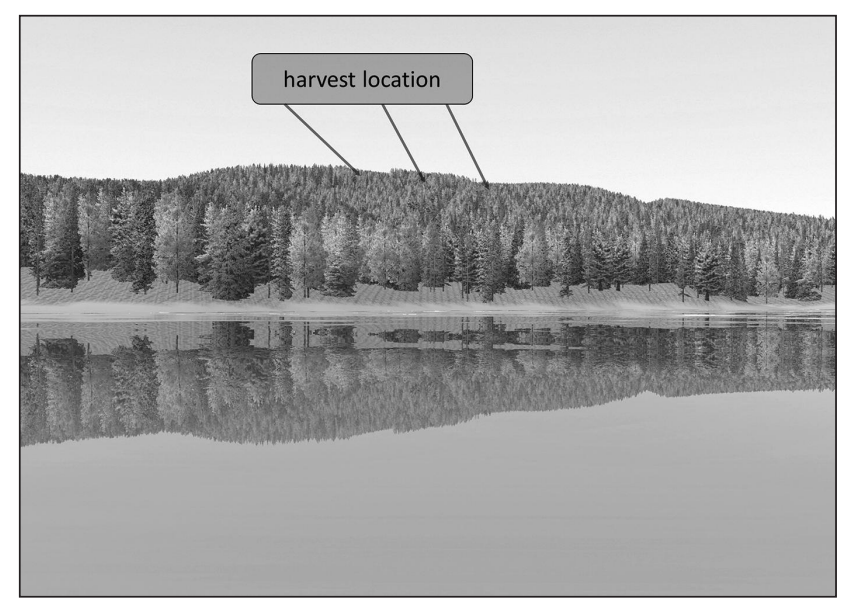

Fig. 7. Example III: 3D rendering from viewpoint 1 showing planned harvest

simulations. VM can help planners speed the design process by allowing them to work in a $2 \mathrm{D}$ environment while showing how an observer might see the topography in 3D space. This allows the planner to not only easily identify visible areas, but also to identify specific places where operations may cause a higher degree of visual impact. With this information the planner will require fewer iterations of block design in order to create a design that fits the VQO requirements, thus reducing the number of $3 \mathrm{D}$ renders needed for each minor change in block design. Another way planning time is reduced is by the reduction in ground-truthing time. Before entering the field, planners knew they would not be harvesting in areas of higher VM, so they did not have to spend time walking these areas. This last aspect of planning could prove quite valuable to companies whose operations consist of large areas protected by a VQO. The advantages of reducing $3 \mathrm{D}$ rending and block design time are useful, but reducing the time spent in the field could prove to be one of the most valuable aspects of this tool.

The second major benefit was the improvement of block design. The mathematics of VM is based on the topography of the landscape as seen from an observer (see Iverson 1985, Grêt-Regamey et al. 2007). This delivers an output which contains a different set of contours than one would see using elevation contours. If the contours formed by VM are followed as a guide, they can help create more naturally appearing boundaries where hard edges are mitigated. This is clearly depicted in Example II. This method can also extend to WTP boundaries. In Example I, these contours were followed simply by placing reserves over the top of the areas of higher VM. In either case, by following the VM output, a more organic and naturally appearing harvest block will be designed.

The third major benefit was how the VM analysis affected the way route-based designs were created. In the past, routes were modeled using a set of pre-defined viewpoints. These viewpoints were meant to best represent the route and were usually identified as providing the greatest exposure to the harvest area from along the route. However, in cases where no viewpoints exist, our analysis can prove to be rather helpful. This is due to the fact that it provides an overview of the topography of the landscape as it may be seen throughout the route and also because, in some cases, visiting the route to

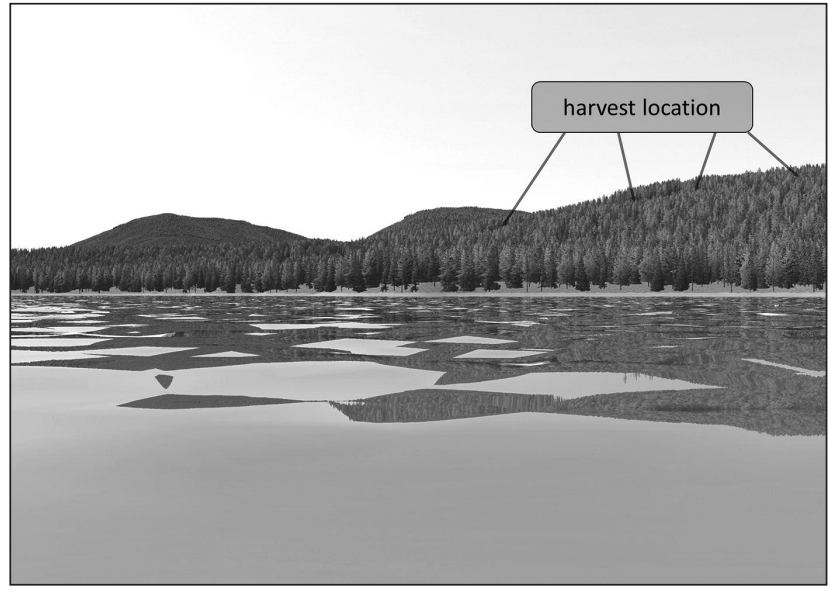

Fig. 8. Example III: $3 \mathrm{D}$ rendering from viewpoint 2 showing planned harvest

identify the more representative viewpoints may be cost prohibitive. For instance, to collect this data for Example III, it would have required a planner to visit and revisit various places along the canoe route to determine the ideal sample viewpoints. This poses all sorts of challenges and difficulties. In drafting an example route, or several example routes, VM can help to identify visible areas and also to determine the degree of visibility.

Working with West Fraser has provided a unique opportunity to bridge the gap between academic research and industry. We anticipate continuing to validate the software, to document best-practice methods, and to extend our outreach to other industry partners. With the experience gained from these cases, we plan to carry out additional studies in a greater variety of terrains, vegetation age classes and visual protection conditions and to continue to build a comprehensive guide to the practical application of VM to operational forest practices.

In the longer term, we envision using VM in a system that can interact with planners to aid in the optimization of block design. This will mean automating certain aspects of design and reserve placement (see Chamberlain and Meitner 2009) using various spatial and qualitative constraints which the planner directs. The intent for this system would be to help optimize the ratio of harvestable timber to visual impact, yet still be simple and intuitive enough for planners to use effectively. Ultimately, the broader anticipated outcome for future software development is to aid in the protection of the scenic beauty of our forests in order to provide the public with outstanding areas to enjoy and ultimately to support the health interests of the greater population. By creating a tool to assist planners in building better designs with less effort, we envisage a more natural and pleasing landscape which better balances industrial and social goals.

These case studies are the first actual applications of our methodology in the forest industry, and through these practical applications, we have demonstrated how Visual Magnitude can be used to guide the strategic placement of Wildlife Tree Patches and reserves (Examples I \& II), improve the design of blocks such that they appear more organic and natural (Example II), and evaluate the potential visual impacts as seen from along an important scenic route (Example III). The goal of the partnership was two-fold: first, to continue devel- 
oping the software and improve its relevancy to industry, and second, to evaluate its effectiveness at improving the planning process. We are confident that these goals have been accomplished and, with lessons learned, we aim to continue improving the method and hope to illustrate the benefits that both industry and government can realize from this tool.

While the application of our methodology offers improvements to the harvest planning process, it simultaneously provides a more effective way to mitigate significant visual impacts. The cumulative effect of better design, informed through our methodology, affords an opportunity to improve the overall scenic beauty of places we live in and travel to. The net effect may be more frequent exposure to natural scenic beauty which can help to reduce stress (Ulrich 1986, Ulrich et al. 1991) and consequently improve quality of life.

\section{Acknowledgements}

Appreciation is extended to Allan Bennett, Greg Scott and Morgan Chenier of West Fraser Timber Mills in Quesnel, BC for their support, collaboration and experience. Financial support was provided by West Fraser Timber Mills and the National Science and Engineering Research Council of Canada.

\section{References}

BC Ministry of Forests. 1994a. A first look at visually effective green-up in British Columbia: A public perception study. Victoria, BC: Forest Practices Branch and Recreation Branch. Available from: https://www.for.gov.bc.ca/hfd/pubs/Docs/Mr/Rec/Rec008.pdf

BC Ministry of Forests. 1994b. Visual impact assessment guidebook: Completing visual force and land feature analyses (appendix 4). Victoria, BC: Forest Practices Branch. Available from: https:// www.for.gov.bc.ca/tasb/legsregs/fpc/fpcguide/visual/via10014.htm BC Ministry of Forests. 1994c. Visual impact assessment guidebook: Visual impact assessment summary form (appendix 2). Victoria, BC: Forest Practices Branch. Available from: https://www. for.gov.bc.ca/tasb/legsregs/fpc/fpcguide/visual/via10012.htm\#E9E11 BC Ministry of Forests. 1994d. Visual landscape design training manual. Victoria, BC: Forest Practices Branch and Recreation Branch. Available from: https://www.for.gov.bc.ca/hfd/pubs/docs/ $\mathrm{mr} / \mathrm{Rec} 023 . \mathrm{htm}$

BC Ministry of Forests. 1996. Clearcutting and visual quality: A public perception study. Victoria, BC: Forest Practices Branch and Recreation Branch. Available from: https://www.for.gov.bc.ca/ hfd/pubs/docs/frr/Frr270_1.pdf

BC Ministry of Forests. 1997a. Visual impacts of partial cutting. Victoria, BC: Forest Practices Branch and Forest Development Section. Available from: https://www.for.gov.bc.ca/hfp/values/visual/ publications/Visual_Impacts-Partial_cut.pdf

BC Ministry of Forests. 1997b. Visual landscape inventory procedures and standard manual. Victoria, BC: Forest Practices Branch and Forest Recreation. Available from: https://www.for.gov.bc.ca/ hts/risc/pubs/culture/visual/vli.pdf

BC Ministry of Forests. 2001a. Bear Lake integrated visual design plan. Victoria, BC: Penticton Forest District Forest Practices Branch Available from: https://www.for.gov.bc.ca/hfp/publications/00039/ ivdp-summary.pdf

BC Ministry of Forests. 2001b. Visual impact assessment guidebook. Victoria, BC: Forest Practices Branch. Available from: https://www.for.gov.bc.ca/tasb/legsregs/fpc/fpcguide/VISUAL/VIA01.pdf BC Ministry of Forests. 2004. Forest and range practices act: Forest planning and practices regulation. In: Forests B. Mo (editor). Victoria, BC: Queen's Printer. Available from: http://www. bclaws.ca/civix/document/id/complete/statreg/14_2004
Chamberlain, B.C. and M.J. Meitner. 2009. Automating the visual resource management and harvest design process. Landscape and Urban Planning 90(1-2):86-94. doi:10.1016/j.landurbplan.2008.10.015 Chamberlain, B.C and M.J. Meitner. 2013. A route-based visibility analysis for landscape management. Landscape Urban Plan. 111: 13-24. doi:10.1016/j.landurbplan.2012.12.004

Duxbury, L. and C. Higgins. 2001. Work-life balance in the new millennium: Where are we? Where do we need to go? Canadian Policy Research Network Ottawa. Available from: http://cprn.org/documents/7314_en.PDF

Frumkin, H. 2001. Beyond toxicity: human health and the natural environment. Am. J. Prev. Med. 20(3): 234-240. Available from: http://www.ncbi.nlm.nih.gov/pubmed/11275453

Grêt-Regamey, A., I. Bishop and P. Bebi. 2007. Predicting the scenic beauty value of mapped landscape changes in a mountainous region through the use of GIS. Environ. Plan. B: Planning and Design 34: 50-67. doi:10.1068/b32051

Iverson, W. 1985. And that's about the size of it: visual magnitude as a measurement of the physical landscape. Landscape Journal 4(1): 14. doi: $10.3368 /$ lj.4.1.14

Kaplan, S. 1995. The restorative benefits of nature: toward an integrative framework. J. Environ. Psychol. 15(3): 169-182. doi:10.1016/ 0272-4944(95)90001-2

Li, Q., K. Morimoto, A. Nakadai, H. Inagaki, M. Katsumata, T. Shimizu, Y. Hirata, K. Hirata, H. Suzuki and Y. Miyazaki. 2007. Forest bathing enhances human natural killer activity and expression of anti-cancer proteins. Int. J. Immunopath. Ph. 20(2 Suppl.): 3-8. Available from: http://www.ncbi.nlm.nih.gov/pubmed/17903349 Li, Q., K. Morimoto, M. Kobayashi, H. Inagaki, M. Katsumata, Y. Hirata, K. Hirata, T. Shimizu, Y. Li and Y. Wakayama. 2008a. A forest bathing trip increases human natural killer activity and expression of anti-cancer proteins in female subjects. J. Biol. Reg. Homeos. Ag. 22(1): 45-55. Available from: http://www.ncbi.nlm. nih.gov/pubmed/18394317

Li, Q., K. Morimoto, M. Kobayashi, H. Inagaki, M. Katsumata, Y. Hirata, K. Hirata, T. Shimizu, Y. Li and Y. Wakayama. 2008b. Visiting a forest, but not a city, increases human natural killer activity and expression of anti-cancer proteins. Int. J. Immunopath. Ph. 21(1): 117-127. Available from: http://www.ncbi.nlm.nih.gov/ pubmed/18336737

Marc, J. 2008. Protocol for Visual Quality Effectiveness Evaluation: Procedures and Standards. Victoria, BC. Available from: https://www.for.gov.bc.ca/HFP/frep/site_files/indicators/IndicatorsVisualQuality-Protocol-Nov2008.pdf

Parsons, R. 1991. The potential influences of environmental perception on human health. J. Environ. Psychol. 11(1): 1-23. doi:10.1016/S0272-4944(05)80002-7

Parsons, R. and T.C. Daniel. 2002. Good looking: in defense of scenic landscape aesthetics. Landscape Urban Plan. 60(1): 43-56. doi:10.1016/S0169-2046(02)00051-8

Radeloff, V.C., R.B. Hammer and S.I. Stewart. 2005. Rural and suburban sprawl in the US Midwest from 1940 to 2000 and its relation to forest fragmentation. Conserv. Biol. 19(3): 793-805. doi: 10.1111/j.1523-1739.2005.00387.x

Statistics Canada. 2003. Mental health and wellbeing. Ottawa. Available from: http://www.statcan.gc.ca/pub/82-617-x/index-eng.htm Travis, M., G. Elsner, W. Iverson and C. Johnson. 1975. VIEWIT: computation of seen areas, slope, and aspect for land-use planning. Berkeley, California, USA: USDA Forest Service No. PSW-11.

Ulrich, R.S. 1986. Human responses to vegetation and landscapes. Landscape Urban Plan. 13: 29-44. Available from: http://www. treesearch.fs.fed.us/pubs/27276

Ulrich, R.S., R.F. Simons, B.D. Losito, E. Fiorito, M.A. Miles and M. Zelson. 1991. Stress recovery during exposure to natural and urban environments. J. Environ. Psychol. 11(3): 201-230. doi:10. 1016/S0272-4944(05)80184-7 